\title{
DIÁLOGO ENTRE MARXISMO E ERGOLOGIA: ANÁLISE E INTERVENÇÃO NO TRABALHO À LUZ DO CONCEITO DE ATIVIDADE
}

\section{DIALOGUE BETWEEN MARXISM AND ERGOLOGY IN WORK ANALYSIS AND INTERVENTION IN THE LIGHT OF THE} ACTIVITY CONCEPT

DIÁLOGO ENTRE MARXISMO Y ERGOLOGÍA: ANÁLISIS E INTERVENCIÓN EN EL TRABAJO A LA LUZ DEL

CONCEPTO DE ACTIVIDAD

\author{
DIAS, Deise de Souza ${ }^{1}$ \\ SILVA, Jurandir Soares da² \\ VERÍSSIMO, Mariana ${ }^{3}$
}

\section{RESUMO}

A partir dos resultados de investigações já realizadas pelo Grupo de Pesquisa Garimpo da Atividade de Trabalho, este artigo propõe uma retomada do diálogo estabelecido entre conceitos marxistas e ergológicos, em torno do trabalho, realizado no âmbito da incorporação da abordagem ergológica no Brasil. São destacados os conceitos marxistas e ergológicos que especificam o trabalho e os diálogos, avanços e limites estabelecidos entre eles. Objetiva-se identificar as repercussões dessas articulações quando se trata de conhecer e intervir no trabalho para transformá-lo.

Palavras-chave: Ergologia. Trabalho. Marxismo. Atividade. Ergoengajamento.

\section{ABSTRACT}

Based on the results of previous investigations from the Research Group "Garimpo da Atividade de Trabalho", it is proposed a resumption of the dialogue established between Marxist and ergological concepts around work, leaded in the ambit of the incorporation of the ergological approach in Brazil. The Marxist and ergological concepts that specify the work and the dialogues, advances and limits established between them are emphasized. It aims to identify the repercussions of these articulations when it comes to understanding and intervening in the work to transform it.

Keywords: Ergology. Work. Marxism. Activity. Ergoengagement..

\section{RESUMEN}

A partir de los resultados de investigaciones ya realizadas por el Grupo de Investigación Garimpo de la Actividad de Trabajo, este artículo propone una reanudación del diálogo establecido entre conceptos marxistas y ergológicos, en torno al trabajo, realizado en el marco de la incorporación del abordaje ergológico en Brasil. Se destacan los conceptos marxistas y ergológicos que especifican el trabajo y los diálogos, avances y límites establecidos entre ellos. Se pretende identificar las repercusiones de esas articulaciones cuando se trata de conocer e intervenir en el trabajo para transformarlo.

Palabras clave: Ergología. Trabajo. Marxismo. Actividad. Ergocompromiso.

\footnotetext{
${ }^{1}$ Rede Municipal de Educação de Belo Horizonte - Belo Horizonte - Minas Gerais - Brasil

${ }^{2}$ Pontifícia Universidade Católica de Minas Gerais - PUC Minas - Belo Horizonte - Minas Gerais - Brasil

${ }^{3}$ Pontifícia Universidade Católica de Minas Gerais - PUC Minas - Belo Horizonte - Minas Gerais - Brasil
} 


\section{INTRODUÇÃO}

A proposta deste artigo tem origem em uma inquietação presente entre os membros do Grupo de Pesquisa Garimpo da Atividade de Trabalho e pode ser apresentada na forma da seguinte questão: em que medida a abordagem ergológica e, mais especificamente, o ergoengajamento, podem ou têm sustentado uma tomada de posição por parte dos ergólogos para o enfrentamento dos problemas que a sociedade brasileira vive nos dias atuais?

Propõe-se, aqui, uma retomada do diálogo entre alguns conceitos marxistas e ergológicos, em torno do trabalho, realizado no âmbito da incorporação da abordagem ergológica no Brasil. Destacamse os conceitos marxianos em torno da dupla trabalho concreto/trabalho abstrato, a fim de averiguar as possibilidades de diálogo entre o pensamento de Karl Marx e os conceitos ergológicos que especificam o trabalho pela ótica da atividade, neste caso, tomando como referência o texto Manifesto por um ergoengajamento (SCHWARTZ, 2016).

Em sua crítica aos economistas clássicos ingleses do século XVIII, cujos maiores expoentes são Adam Smith e David Ricardo, Marx (1978) procura descrever a essência do funcionamento do capital, desvelando as mazelas do capitalismo.

Seguindo pistas deixadas por Georg Hegel, Marx (1978) sustenta que o trabalho é a essência do homem. Adere ao princípio da positividade do trabalho, que seria mais do que processo de dominação daquele que não trabalha sobre aquele que trabalha. O trabalho seria, pois, processo de domínio do homem sobre a natureza e, ao mesmo tempo, processo de domínio de si próprio. Evidencia a dimensão formativa do trabalho, ou seja, a centralidade do trabalho no processo de constituição do ser humano. Nesse sentido, o que distingue o homem dos animais é que a história é um processo de criação, satisfação e recriação contínuas das necessidades humanas. Por isso o trabalho está na base da sociedade humana, como intercâmbio criador entre os homens e o seu ambiente natural. Em Hegel (1992), a concepção genérica e abstrata do trabalho é ultrapassada através de um estudo sobre os modos históricos nos quais se trabalha para satisfazer as necessidades de todos. Assim, é possível evocar a ideia de que o trabalho é formador.

Marx (1978), entretanto, irá além, voltando o seu olhar para as formulações de Smith (1974), para quem o trabalho seria um mero conjunto de simples operações de produção que podem ser definidas antecipadamente, de forma muito precisa, independentemente de quem irá executá-las. Nesse contexto, o trabalhador é reduzido à simples força de trabalho, dotado de energia e habilidades que lhe permitem realizar tais operações. A soma do trabalho de cada indivíduo, em seu setor e em sua posição, evitaria que o caos se estabelecesse e que houvesse desencontro de interesses. Vendo no trabalho humano toda a fonte de riqueza social e de todo valor, os economistas clássicos pretendiam dissociar o operário do homem concreto, reverenciando o homem somente como força de trabalho. Nesse sentido, ocorre uma redução do conceito de trabalho a uma dimensão meramente econômica. 
Ao criticar os economistas clássicos, Marx (1978) irá ressaltar que da mesma forma que a mercadoria apresenta dupla natureza, valor de uso e valor de troca, o trabalho também possui duplo caráter: trabalho concreto/trabalho abstrato. Há distinção, mas também uma íntima inter-relação entre ambos. O primeiro é qualitativo e produz valores de uso necessários ao ser humano, ou seja, produto utilizável, indispensável à produção e reprodução humana, satisfazendo socialmente as suas necessidades físicas e espirituais. Já o trabalho abstrato tem como fim principal a criação de mais valia, a reprodução e autovalorização do capital. Apesar de a estrutura da produção estar dirigida para a criação de valores de uso, no capitalismo, a formação de excedentes transforma tais valores em meios de troca, ou seja, em valores de troca.

Yves Schwartz (1988) irá resgatar essa dupla dimensão do trabalho afirmando que, apesar de opostas, elas não se excluem. Toma o trabalho concreto como referência para a análise do trabalho como atividade humana. Tendo a noção de atividade como categoria central da ergologia, esse autor irá situar o trabalho como manifestação da vida humana e como valor sem dimensão. Seguindo as ideias de Schwartz (2016), envereda-se, aqui, na discussão sobre o ergoengajamento, buscando-se os limites e avanços do diálogo entre o marxismo e a ergologia.

\section{O TRABALHO EM SUA DUPLA DIMENSÃO: CONCRETOIABSTRATO}

Nos Manuscritos de 1844, Marx (1978) faz referência aos limites do pensamento hegeliano, que estariam no fato de que ele ignora a alienação do trabalhador e as contradições de interesses econômicos e materiais presentes na economia capitalista. Para Hegel, a libertação e a dominação seriam concebidas como meras questões de consciência, sendo que a origem da violência entre opressores e oprimidos seria motivada pelo desejo humano espiritual de reconhecimento.

Marx (1978) vai, então, analisar o trabalho na sociedade capitalista, detendo a sua atenção não apenas sobre as relações de dominação entre senhores e escravos, mas principalmente entre a burguesia e o proletariado e, ainda, no trabalho como valor de troca. Desenvolve um esquema argumentativo no qual considera que a mercadoria representa a existência molecular do capital, uma vez que toda a produção capitalista toma a forma de mercadoria que é, ao mesmo tempo, 'valor de uso' e 'valor de troca'.

Nessa perspectiva, o trabalho abstrato e geral seria a fonte do valor de troca e o trabalho concreto e particular seria a fonte da riqueza material, que produz valores de uso. O valor de uso de uma mercadoria tem como pressuposto a sua utilização e a finalidade com a qual se investiu determinado tempo de trabalho em sua produção. No entanto, quando as mercadorias são igualadas como equivalentes gerais, o trabalho gera valor de troca sem, contudo, deixar de ser uma atividade produtiva que tem um objetivo a alcançar.

No capitalismo, segundo Marx (1978), ocorre a redução dos trabalhos a certa uniformidade, desconsiderando-se as diferenças, as individualidades e as particularidades das relações que se tecem 
nas situações reais de produção. Assim, pode-se medir os valores de troca das mercadorias e o que fica evidenciado é o tempo de trabalho nelas contido. Dessa forma, os valores de uso tornam-se equivalentes, desde que contenham o mesmo tempo de trabalho objetivado, ignorando-se que os trabalhos sejam qualitativamente diversos entre si, uma vez que os valores de uso são produtos de trabalho individualmente diferenciados.

Considerar o trabalho apenas em suas características quantitativas é uma abstração praticada diariamente no processo social de produção capitalista. Portanto, a redução do valor das mercadorias ao tempo de trabalho gasto em sua produção é uma abstração social real. Este trabalho não é considerado como sendo o trabalho de diversas pessoas, pois essas seriam meros órgãos do trabalho. Todo trabalho que se apresente como valor de troca possui o caráter social de igualdade, desconsiderando os diferentes indivíduos, e somente é valor de troca enquanto se relacionar, reciprocamente, como igual, com outros trabalhos.

Marx (1978) afirma que no valor de troca o tempo de trabalho individual aparece como tempo de trabalho geral, o qual assume o caráter social do trabalho. Este tempo de trabalho é do indivíduo, que não se distingue dos demais que realizam trabalho igual. Portanto, o tempo de trabalho gasto por um indivíduo para produzir uma mercadoria é o mesmo gasto por qualquer outro para produzir a mesma ou outra mercadoria. É, pois, um tempo de trabalho individual, mas, ao mesmo tempo, comum a todos.

Na perspectiva acima, o tempo de trabalho é considerado o equivalente geral, que faz com que o tempo de trabalho de um indivíduo resulte em valor de troca. Assim, todas as particularidades da produção da mercadoria são negadas, encobrindo a sua forma concreta e natural, as marcas da atividade. Essa forma natural do objeto, que é encoberta num primeiro momento, é imediatamente representada no equivalente, que é o dinheiro.

Na troca mercantil, o tempo de trabalho abstrato é o intermediário entre produtos, sendo reificado como mercadoria. Representa o equivalente geral e não mais um produto, passando o dinheiro a ser também uma mercadoria particular, que representa o modo de ser adequado do valor de troca de todas as mercadorias. Nesse caso, ocorrem uma inversão e uma mistificação que são reais, pois a relação social de produção aparece como objeto existente fora dos indivíduos, e os relacionamentos que ocorrem no processo de produção da vida social emergem como propriedades específicas de uma mesma coisa.

A estrutura da produção está, na verdade, dirigida para a criação de valores de uso, entretanto a formação de excedentes sobre a quantidade necessária de tais valores é que os transforma em valores de troca, em meios de troca.

Schwartz (1988) irá propor o resgate do trabalho a partir de sua dupla dimensão: trabalho abstrato/trabalho concreto, indicando que essas vertentes do trabalho não devem ser analisadas como excludentes. Nesse sentido, a análise marxiana do fetichismo da mercadoria permitiria compreender porque o trabalhador, no ato de trabalho, tende a perceber-se como força de trabalho abstrata, mesmo não deixando de ser parte produtora concreta de valores de uso concretos. Entretanto, tal fetichismo 
não impede que todo ato de trabalho seja, ao mesmo tempo, a obra de homens concretos que mobilizam suas capacidades na produção de objetos úteis diversificados. Apesar de haver um domínio do processo de valorização, o ato produtivo possibilita ver que o trabalho concreto não desaparece, produzindo grandes efeitos sobre o trabalhador, sendo possível pensar a junção entre abstrato e concreto dentro da unidade de uma personalidade.

O trabalho como objeto de estudo, segundo Schwartz (1988, 2008), tem sido pensado pelas filosofias da história e dos marxismos a partir de sua dimensão abstrata. Tais interpretações, apesar de não refletirem, necessariamente, a real essência do pensamento marxiano, são essenciais para a compreensão do movimento histórico a partir de determinações econômicas, jurídicas e processuais. A noção abstrata do trabalho permite, ainda, a sua inserção no quadro histórico das relações capitalistas de produção, centrada na dicotomia trabalho assalariado/capital. Entretanto, ainda de acordo com Schwartz (1988, 2008), é preciso atentar para que essa perspectiva não impeça de enxergar o trabalho como uma das formas de atividade humana, a fim de que não sejam suprimidas as singularidades aí presentes.

Há, de acordo com esse autor, um silêncio dos marxismos sobre essa especificidade temática, ainda que a relação entre história e trabalho tenham sido centrais na obra de Marx. Para Schwartz (1988), isso constitui um paradoxo, pois não é fácil encontrar fora do marxismo um referencial teórico que possa contribuir para uma discussão mais ampla. Assim, apesar de criticar as análises marxistas que abordam a história como uma sucessão dos modos de produção, Schwartz (1988) se propõe a averiguar as contribuições de Marx para esse debate. Por um lado, procura ver a contribuição do pensamento marxista na análise das formas específicas do trabalho em si mesmo e, por outro, busca retrabalhar os seus conceitos a fim de averiguar como eles podem contribuir de forma adequada para o aprofundamento do conhecimento sobre o que vem a ser o trabalho humano.

Schwartz (1988) entende que, para Marx, o trabalho somente toma forma na história quando analisado no interior de um processo de produção particular, sendo que o essencial do trabalho ocorre na articulação entre trabalho concreto e trabalho abstrato. Essas duas formas, presentes e opostas num mesmo trabalho, como as duas faces de uma mesma moeda, não se excluem. Os conceitos de força produtiva, relação de produção e modo de produção evidenciam o processo histórico de investimento no trabalho da espécie humana. Entretanto, não há eliminação da dimensão concreta do trabalho, mas sua devida articulação com as determinações mais abstratas do processo histórico. Com o conceito de processo de trabalho, Marx articula três esferas ligadas ao trabalho: a atividade pessoal do homem ou trabalho propriamente dito; o objeto sobre o qual o trabalhador age; os meios pelo qual ele age.

Assim, quando a ênfase recai sobre o trabalho concreto e o processo de trabalho, é possível resgatar a dimensão de criação e transformação do sujeito pelo trabalho. $\mathrm{E}$, ainda, dialeticamente, a dimensão de criação e transformação do trabalho pelo sujeito. O enfoque do trabalho a partir da sua dimensão concreta torna-se importante por permitir evidenciar quais são as condições cotidianas de mobilização do corpo-si. 
O que interessa nessa discussão é destacar que a abordagem abstrata do trabalho feita por Marx (1978) influenciou fortemente os estudos sobre o trabalho no Brasil, levando os teóricos a tecerem análises que dificultavam destacar as dramáticas do uso do corpo-si presentes na atividade de trabalho. A ergologia, com suas análises sobre o trabalho, irá permitir o resgate da dimensão concreta e a emergência do corpo-si, fazendo com que o trabalhador não seja tratado apenas como mercadoria e, ainda, que a atividade concreta de trabalho não fique subsumida por esse viés abstrato.

\section{ERGOENGAJAMENTO: POSSIBILIDADES E LIMITES PARA A TRANSFORMAÇÃO SOCIAL}

Retoma-se aqui o Manifesto por um Ergoengajamento (SCHWARTZ, 2016), salientando-se que o termo manifesto, que intitula o referido texto é, segundo o autor, uma declaração que exige uma tomada de posição ao se identificar os conteúdos nele explicitados. Schwartz (2016) propõe-se a sintetizar uma reflexão sobre a posição daqueles que assumem um olhar orientado pela abordagem ergológica a respeito da humanidade no trabalho e, com o objetivo de sustentar um posicionamento ergoengajado, irá apresentar e discutir algumas condições. Uma dessas condições é considerar a atividade como "uma noção que atravessa, transgride, religa todas as fronteiras no interior do ser humano; um poder de mediação entre cada nível da experiência humana; uma dinâmica de contradições potenciais, uma matriz de toda historicidade humana" (SCHWARTZ, 2007, p. 130).

Portanto, não se pode pensar o humano sem levar em conta o ponto de vista da atividade, pois ele é atingido por debates internos ou debates de normas e valores. Tais debates podem ser mais ou menos visíveis ou invisíveis, conscientes ou não, explicitados ou escondidos nos meandros do corposi. Recusar que a humanidade é atravessada por esses debates é abrir espaço para toda espécie de violência econômica, social e política.

Schwartz (2016) considera a atividade uma convidada fecunda e constrangedora com a qual não haveria problema se a racionalidade das normas considerasse o trabalho humano como potencialidade de manifestação da diversidade e complexidade específica do homem, permitindo, assim, que cada um arbitrasse, em seu íntimo, suas escolhas. Dessa forma, o trabalho humano não seria, jamais, tomado como mera execução. O necessário convite à atividade remete às urgências de se posicionar e fazer escolhas com base em valores. A dimensão dramática da atividade implica em considerar que nada que diz respeito ao humano é mecânico e pré-determinado. A tentativa de mecanização e de predeterminação presente na racionalidade das normas nega e trai a humanidade de homens e mulheres cuja existência se torna esmagada.

Convidar a atividade para ser protagonista de todas as avaliações que se faz do humano é também um convite a não negligenciar as normas que fazem parte do patrimônio histórico da humanidade. Segundo Schwartz (2016, p. 331) "a normalização é uma conquista de toda sociedade humana" porque ela expressa a capacidade das pessoas se posicionarem e colocarem em palavras os saberes investidos que se tornarão, por meio das normas, saberes constituídos e disponíveis para 
todos. Confrontar com as normas é uma condição fundamental para sobreviver e viver em sociedade, visto que elas são criadas nas e pelas histórias especificamente humanas.

O humano não deve e não pode se abdicar da possibilidade que veio sendo construída social e historicamente, na experiência existencial do homem, de intervir no mundo e de antecipar. No entanto, isso não é suficiente, as normas não dão conta dos imprevistos porque a vida se faz a cada instante, se transforma e requer renormalizações. Portanto, a renormalização faz parte da atividade, fora da qual não há trabalho humano, o que impõe tentar entendê-la na ou nas suas razões de ser, fazer a crítica para cumprir a norma ou renormalizar em relação ao meio e no aqui e agora. É necessário esforçar-se para compreender a norma, sabendo que o humano não é apenas objeto dela e que ela não é apenas resultado de decisões voluntaristas de pessoas ou grupos. É pela renormalização que se pode transformar o trabalho, pois "nenhum protocolo, nenhuma norma antecedente, nenhuma prescrição poderá abstrair os vazios de normas." (SCHWARTZ, 2016, p. 333).

$\mathrm{Na}$ atividade ocorrem debates de normas que se dão em função dos valores que cada pessoa construiu para si. É em função dos valores que cada um estabelece critérios para fazer escolhas. Os debates internos, baseados nos valores, criam normas quando elas não existem ou quando elas são insuficientes e renormalizam quando é necessário adequá-las às situações concretas. Os valores podem ser identificados segundo duas categorias distintas: os sem dimensões e os quantitativos. Schwartz considera como valores sem dimensões aqueles que são inerentes às dramáticas da atividade e são construídos nas experiências vividas por cada pessoa. Eles só existem associados aos protagonistas da atividade e às suas vivências. Por sua vez, os valores quantitativos podem ser antecipados e são necessários para a atividade humana. Estes, ao contrário dos valores sem dimensão, embora possam ser igualmente escolhas, são construídos em desaderência às situações reais de trabalho e, juntamente com os primeiros, inspiram as normas antecedentes. Assim, "escolher ganhar mais em detrimento de seus vizinhos de trabalho, ganhar um bônus com risco para sua saúde, permanecem escolhas." (2016, p. 339).

No que se refere à relação entre o dinheiro e a atividade, Schwartz (2016) afirma que existe uma contradição que está no fato de que o mercado age visando produzir e aumentar o lucro. Para alcançar esse objetivo, elabora normas rígidas e controladas que não consideram as singularidades e nem os dramáticos debates de valores, levando à desumanização provocada pelo "dinheiro-rei".

Schwartz (2016), ao discutir os termos “cacofonia" ou "demagogia ergológica”, conclui que eles se referem a um risco, uma cegueira antropológica, de se valorizar em excesso as renormalizações e alguns saberes dos trabalhadores. Isto porque, em um determinado momento, as cristalizações provisórias "podem, em certos casos, se comportar como excludentes e até sustentar práticas de assédio no trabalho" (Schwartz, 2016, p. 350). Assim, ao fazer o "elogio das normas", ressaltando que as mesmas são necessárias e não são as vilãs e nem sempre são causas de doenças e do mau funcionamento do processo produtivo, Schwartz observa que o humano em trabalho está sujeito ao erro em suas cristalizações e renormalizações, pois thá momentos em que os valores próprios dos protagonistas, aqueles que pesam sobre as renormalizações, são incômodos, irresponsáveis, em outra 
palavra, 'discutível'." (2016, p. 350). Portanto, a renormalização pode apresentar aspectos positivos e negativos. Um aspecto negativo seria uma pessoa mal-intencionada renormalizar para prejudicar o desenvolvimento do trabalho e um positivo, e desejável, é a pessoa renormalizar para favorecer o desenvolvimento do trabalho.

Do mesmo modo que posicionar-se de maneira a considerar o ergoengajamento requer ficar atento para não ceder à demagogia ergológica, deve-se, também, evitar a ingenuidade ou angelismo. O olhar ergológico sobre a humanidade no trabalho, o posicionar solenemente não é angelismo. É uma postura de humildade, reconhecendo que o que eu sei, que as normas antecedentes que eu incorporei, podem passar por atualizações, podem ser renormalizadas no aqui e agora da atividade. Redescobrir a humanidade é reconhecer que o humano está sujeito a erros e acertos, e que pode também agir inescrupulosamente ou se mostrar solidário. Compreender que "os humanos aqui e agora não são todos iguais, é o mínimo que se pode dizer, em suas responsabilidades e em sua disponibilidade para agir sobre a contradição dinheiro/atividade; para mantê-la, ampliá-la ou reduzi-la" (SCHWARTZ, 2016, p. 351).

Com base nas considerações anteriores, Schwartz propõe o ergoengajamento como "um militantismo paradoxal já que se trata de se engajar para avaliar as capacidades de uma realidade que já existe bem antes que se fale dela" (SCHWARTZ, 2016, p. 367).

Se por um lado o engajamento, numa perspectiva marxista, implica na busca da superação da divisão de classes, da alienação, das condições degradantes do trabalho, frutos da forma de conceber e organizar o trabalho sob a ótica capitalista, por outro, na perspectiva do ergoengajamento, a tônica recai sobre a renormalização, ou seja, na superação da fragmentação do trabalho e da heterodeterminação. Isto significa que o trabalhador é sujeito ativo e quer ser sujeito das suas próprias normas. Portanto, não recebe de maneira passiva tudo o que é imposto por aqueles que gerem e definem o trabalho (SCHWARTZ, 2007).

Schwartz (2016) acredita que suas ideias são pertinentes para ajudar a pensar alternativas para as questões propostas pelas sociedades atuais. $\mathrm{O}$ autor questiona as categorias que se propõem a apresentar respostas comuns a problemas específicos como nacionalidade, divisão de classes, desigualdade, entre outras que, até um determinado momento histórico, foram suficientes para explicar os problemas do mundo comum. Por isso ele não se propõe a apresentar categorias de análise ou de ações que conduzam à superação das contradições sociais, e afirma que "funcionar como categoria leva a nunca singularizar, leva, portanto, a evitar as dramáticas sempre parcialmente locais, individuais, os cadinhos onde estão em jogo, permanentemente, as contradições de nossa história" (SCHWARTZ, 2016, p. 348). O autor considera que as categorias são usadas para se agir de forma coerente e homogênea, entretanto, ressalta que seres históricos reais não são homogêneos e nem sempre coerentes.

Por isso Schwartz (2016), ao propor o Manifesto por um Ergoengajamento, considera como questão necessária ajustar a lente da atividade para se aproximar das ações concretas no mundo político. Essas ações concretas não se efetivariam sem intervenção nos regimes de produção de 
saber. E tal intervenção só é possível quando a atividade é convidada, visto que ela possibilita captar os saberes investidos e todo um patrimônio de saberes em penumbra, tais como os funcionamentos reais, as histórias de encontros e as trajetórias de saúde ou de mal-estar.

Uma postura de ergoengajamento é aquela que milita no sentido de propor Dispositivos Dinâmicos de Três Polos - DD3P, que promove a confrontação de saberes, no intuito de fazer emergir os saberes em penumbra. O objetivo do DD3P é de "incitar aqueles que vivem e trabalham a colocar em palavra um ponto de vista sobre sua atividade" (SCHWARTZ, 2016, p. 364). Assim, a transformação da sociedade inicia-se em cada pessoa ergoengajada que se propõe a fazer dialogar os saberes constituídos e os saberes investidos. Nesse diálogo, que promove o desinvestimento dos saberes investidos ao colocá-los em palavras, os saberes constituídos se atualizam e se modificam. Assim, embora no nível mais evidenciado do micro, promovem-se mudanças no macro.

O ergoengajamento se constrói com base em mudanças de concepções provocadas nos diálogos socráticos de sentido duplo, que pressupõem um desconforto intelectual. Essas concepções, que podem ser relativas à humanidade do outro e à própria humanidade, conduzem a reconhecer o outro como seu semelhante. Portanto, não se trata de um posicionamento escolhido espontaneamente por quem decide ser ou não engajado do ponto de vista da atividade. Não basta conhecer e dominar os conceitos da ergologia para assumir tal postura. É possível que pessoas, embora do ponto de vista do registro escrito façam usos das noções desenvolvidas por Schwartz, mantenham uma postura de poder e de dominação em relação a outras quando trata-se do seu agir, das relações interpessoais que estabelecem, do viver em sociedade ou do bem comum.

Nesse sentido, segundo Schwartz (2016), o ergoengajamento não seria um posicionamento pragmático que direciona para as questões micro, afastando-as das questões macro. Pois, ao enfatizar o ponto de vista da atividade, os debates de normas e as dramáticas de usos de si, a ergologia não deixa subsumidos os desafios postos pelos campos político, econômico e social que incidem na dialética entre o trabalho abstrato e o concreto. A esse respeito Schwartz afirma que "enquanto não nos damos como motivo político ajudar a desdobrar a riqueza dos debates de normas ergológicas, em suma, enquanto ainda não se está engajado, a relação dos cidadãos com o político, através dos canais extremamente pré-formatados, é pobre" (2016, p. 362).

O resgate que se faz aqui do Manifesto por um Ergoengajamento (SCHWARTZ, 2016) foi realizado com o intuito de adentrar a indagação que originou este artigo: em que medida a abordagem ergológica e, mais especificamente, o ergoengajamento, podem sustentar uma tomada de posição dos ergólogos para o enfrentamento dos problemas que a sociedade brasileira vive nos dias atuais?

\section{CONSIDERAÇÕES FINAIS}

A sociedade brasileira vive, atualmente, problemas graves, reflexo do golpe de Estado iniciado em 2016 e que encontra-se em curso no país. Entre eles citam-se a ausência de um projeto societário 
emancipatório, o recrudescimento da desigualdade social, as situações degradantes de trabalho, a perda de direitos trabalhistas historicamente conquistados, o retrocesso nas políticas públicas de inclusão social e no diálogo com os movimentos sociais, a redução dos investimentos em educação e saúde, a atuação criminosa no âmbito do poder legislativo e partidária no poder judiciário, além do ataque à soberania nacional.

Essa realidade repõe um princípio básico para os ergólogos, agora em novos termos: conhecer e transformar o trabalho para quê e em que direção? $E$, em consequência, como agir de maneira ergoengajada para intervir e transformar a sociedade brasileira, para além do trabalho?

A inquietação que este artigo procurou fazer circular tem respaldo no conjunto de pesquisas ${ }^{4}$ realizadas pelo Grupo de Pesquisa Garimpo da Atividade de Trabalho, que voltaram-se para a análise da incorporação da ergologia no Brasil. Entre elas salienta-se aquela denominada Percursos da Ergologia no BrasiF (DIAS et al, 2017), que contou com o depoimento de 68 pesquisadores, estudantes e trabalhadores brasileiros, inseridos em diversas áreas do conhecimento, em instituições públicas e privadas.

A referida pesquisa indicou que a ergologia tem mobilizado um número expressivo de pessoas no Brasil, desde 1997, ano da sua introdução no país. Seus resultados mostram que a incorporação dessa abordagem produziu algum efeito no trabalho dos depoentes e no trabalho das pessoas com as quais eles trabalham ou trabalharam. Ressalta-se um reposiciornar-se do ergólogo com e no próprio trabalho com repercussões, em alguns relatos, na vida como um todo.

Foram descritas modificações na gestão acadêmica e nos processos de ensino e aprendizagem inerentes à docência; na consideração do trabalhador como protagonista de seu próprio trabalho e saúde, no âmbito das políticas públicas; na atenção aos saberes que permeiam as situações de trabalho e necessitam da sustentação de um posicionamento ético, político e subjetivo por parte dos trabalhadores. Na maioria dos relatos, o realce é atribuído a modificações na dimensão micro das situações de trabalho.

Os resultados da pesquisa permitem afirmar que, quando se trata de uma incorporação do ponto de vista teórico, a abordagem ergológica levou os pesquisadores a considerarem as dimensões micro/macro e suas articulações nas situações de trabalho. Contudo, ao tratar-se do ponto de vista da intervenção, o terreno atingido é o micro.

Quando os depoentes relataram as dificuldades da incorporação da ergologia em pesquisas e intervenções, destacaram sempre os limites dessa abordagem no que concerne à dimensão macro do trabalho.

\footnotetext{
${ }^{4}$ Essas pesquisas destacaram as contribuições e os limites da ergologia em campos diversos do conhecimento, do ponto de vista conceitual, metodológico e da intervenção; a existência, nas dissertações e teses analisadas, de interpretações variadas do conceito ergológico de atividade; e o debate de normas como conteúdo de uma atividade humana singular, expressa em uma situação de trabalho docente.

${ }^{5}$ Itineraires de l'ergologie au Brèsil.
} 
Ao problematizar a incorporação da ergologia pelos ergólogos, os autores deste artigo pensam que, sob o domínio do capital, apesar dos ganhos de natureza singular e, às vezes, até coletivos, expressos na dimensão micro, as transformações alcançadas no trabalho não alteram as relações capitalistas de produção inscritas na dimensão do macro. Pode-se até cogitar que há uma tendência de consolidação de tais relações, já que as transformações produzidas criam ambientes que podem somente apaziguar as contradições entre macro e micro, entre trabalho abstrato e trabalho concreto.

Sem pretender dar repostas e muito menos esgotar o assunto, propõe-se uma discussão em torno das seguintes questões: pode-se esperar que a proposta da ergologia, de articulação entre o macro e o micro, possibilite aos trabalhadores, entre eles os ergólogos, um engajamento que fomente a transformação das relações capitalistas de produção? Pode-se esperar que o viés do trabalho concreto deixe de subsumir o viés do abstrato nas intervenções realizadas a partir da abordagem ergológica? Pode-se, a partir das micro transformações nas situações de trabalho, extrair alternativas concretas e viáveis para a superação das desigualdades sociais e da exploração capitalista? Pode-se ultrapassar as análises e intervenções no nível micro e indicar caminhos para a superação da sociedade de classes?

Ao finalizar este texto os autores, que se consideram ergólogos, ousam dizer que, da mesma forma que Marx deixou o trabalho concreto esmaecido em relação ao trabalho abstrato, os ergólogos tendem a fazer o oposto: focalizam o trabalho concreto mas não sabem o que fazer com o que se inscreve nele do trabalho abstrato, razão pela qual convidam os ergólogos a revisitarem a proposta do ergoengajamento e a proposta marxiana de transformação social.

\section{REFERÊNCIAS}

1. $\quad$ DIAS, Deise de S.; et al. Itineraires de l'ergologie au Brèsil. Ergologia, n. 18, p. 253-262, 2017.

2. HEGEL, Georg W. F. Fenomenologia do Espírito. Parte 1. Petrópolis: Vozes, 1992.

3. MARX, Karl. Manuscritos econômico-filosóficos e outros textos escolhidos. Tradução de José Carlos Bruni et al. 2. ed. São Paulo: Abril Cultural, 1978.

4. SCHWARTZ, Yves. Manifesto por um ergoengajamento. In: SCHWARTZ, Yves e DURRIVE, Louis. Trabalho e Ergologia II: diálogos sobre a atividade humana. Belo Horizonte: Fabrefactum, 2016. 
7. O trabalho numa perspectiva filosófica. In: NOZAKI, Izumi (Org.) Educação e Trabalho: trabalhar, aprender, saber. Campinas: Mercado de Letras, 2008.

8. SMITH, Adam. Investigação sobre a Natureza e as Causas da Riqueza das Nações. São Paulo: Abril Cultural, 1974.

\section{Deise de Souza Dias}

Mestrado e Doutorado pela Faculdade de Educação da Universidade Federal de Minas Gerais. Professora da Rede Municipal de Educação de Belo Horizonte. Membro da Sociedade Internacional de Ergologia.

\section{Jurandir Soares da Silva}

Pedagogo, Mestre em Educação/Ergologia. Professor nas licenciaturas e Pós-graduação lato sensu (docência do Ensino Superior).

\section{Mariana Veríssimo}

Mestrado em Ensino de Ciências e Matemática Colaboradora do PROMESTRE/FAE-UFMG.

\section{Como citar este documento:}

DE SOUZA DIAS, Deise; SOARES DA SILVA, Jurandir; VERÍSSIMO, Mariana. Diálogo entre Marxismo e Ergologia: análise e intervenção no trabalho à luz do conceito de atividade. Reflexão e Ação, Santa Cruz do Sul, v. 26, n. 3, nov. 2018. ISSN 1982-9949. Disponível em: $<$ https://online.unisc.br/seer/index.php/reflex/article/view/12495>. Acesso em: 19 nov. 2018. doi:https://doi.org/10.17058/rea.v26i3.12495. 